\title{
1
}

\section{Information Systems and Qualitative Research}

\author{
A. S. Lee \\ McGill University \\ Montreal, Quebec, Canada H3A 1 G5 \\ Tel: $\quad$ (514) 398-4012 \\ Fax: (514) 398-3876 \\ E-mail: AllenLee@Management.McGill.ca
}

\section{J. Liebenau}

Department of Information Systems

London School of Economics

London WC2A $2 A E$ England

Fax: 441719557385

E-mail: J.L.Liebenau@lse.ac.UK

Most mature social studies include both qualitative and quantitative methods in the normal course of research activities. Scholars may gain reputations based on one or the other, or in some cases on the combination of both. In fields such as sociology, psychology, history, political science, and even anthropology the balance has been struck; the rules are accepted. Business studies in general, and information systems in particular, have had a much harder time coming to terms with the balance. With so many colleagues using exclusively quantitative methods in business economics, in marketing, in accounting and even in organizational behavior, and other colleagues sticking strictly to formal methods in computer science and software engineering, we have had to fight an uphill battle at times. This volume is evidence of the maturing of information systems as a discipline which can recognize the place of qualitative along with quantitative research methods.

Qualitative research in information systems has been manifested in a wide variety of ways, as is exemplified in this volume. Since the 1970s, and arguably even before, 
systems researchers have looked to other disciplines to apply qualitative methods to problems such as decision making, users' responses to computing, and man-machine interfaces. Only recently, however, has it seemed necessary to try to define what qualitative research essentially is and even more urgently, to defend it against those who ignore or denigrate it. Qualitative research in information systems must in each instance reconcile two forces. The first is the technique and standard that is expected in the discipline from which the method is taken. The second is to ensure that the technique, or the associated theoretical baggage from that other discipline, does not diminish the information systems purpose and importance. This is not an easy task. Sometimes we feel that the issue at stake is so pertinent to information systems as a discipline that we can or should overlook or circumvent the standards that the contributing discipline applies. At other times we are so taken up by the techniques that have proven so effective in sociology, for example, that we lose sight of the information systems issues we started with. The papers in this volume, we believe, do not suffer from either of these shortcomings.

What links these papers is first and foremost a community of information systems researchers who have a set of shared interests. It is not so easy to characterize that common interest, especially since most authors personally know only a few of the other authors. One commonality is a commitment to information systems research of high quality. This distinguishes them from those who regard research to be an activity peripherial to teaching and consulting. Another feature is their willingness to attempt qualitative methods. Most of our authors have been engaged in other forms of research, and it would not be right to assume that all of them are devoted to qualitative methods alone. We see this as a strength, and further evidence of the new maturity which we are coming to accept.

The topic of information systems and qualitative research is problemmatic now in at least three ways: in the challenge which information systems poses to traditional research approaches; in the new diversity which is emerging; and in the way in which it calls into question the impact of previous qualitative work.

First, information systems [IS] phenomena have posed serious problems to traditional research approaches in the development of scholarly knowledge about IS. These phenomena have defied the power of traditional research approaches to explain how individuals, groups, organizations, nations and society as a whole can harness computer technology to serve humanity. In Sciences of the Artificial, Herbert Simon points out that once a bridge begins to strain under a load greater than it was designed to bear, observers can take advantage of the situation to learn about the materials with which the bridge was constructed and the manner in which it was built. A bridge functioning normally, however, would present no similar opportunity for observation and insight. In much the same way, IS phenomena have come to constitute a load greater than traditional research approaches, alone, were ever intended to bear. IS researchers employing these approaches have fallen short of being able to provide full and satisfactory accounts of the success, failure, effectiveness, efficiency, freedom, and subjugation that occur in instantiations of computer technology in everyday life. In this situation, it is not surprising that the focus of attention should shift, at least 
temporarily, from IS phenomena to the research approaches by which researchers come to try to understand these phenomena.

Two earlier meetings of Working Group 8.2 of the International Federation for Information Processing (in Manchester in 1984 and in Copenhagen in 1990) convincingly established that IS phenomena have stretched traditional research approaches to, and even beyond, their limits. These two meetings took advantage of the situation to throw open to question, and no longer assume or take for granted, what constituted the traditional research approaches. These approaches were typically those associated with the supposed natural science model of social science research and were labeled (often inaccurately) "positivist," "quantitative," "experimental," and "hypotheticodeductive." While there has been great success in applying natural science and engineering models to research into computer technology, they have been inadequate and inappropriate in explaining the human, group, organizational and societal matters which surround the use of information systems. These matters have come to constitute a load that natural scientists and engineers themselves never intended their research methods to bear.

The Manchester and Copenhagen meetings were milestones in the effort to inaugurate additional research approaches needed to explain and understand information systems. These meetings have lifted some of the burden for qualitative researchers to justify the need for or the legitimacy of their approaches. In the current volume, the authors proceed quickly, assertively and unapologetically to the next steps of applying and refining qualitative research approaches.

Second, as is reflected in these papers, there is an emerging acceptance of diversity in research approaches. Whereas the term "qualitative" once carried the connotation of "anti-positivist," there is qualitative research in this volume that draws confidently upon positivism or other forms of deductivist approaches. For some this is problemmatic, but for others it is expedient, or merely the approach which best seems to solve the problems of evidence gathering in their research domain. Paré and Elam conduct a case study which they say "adopts a positivist view of research in that it is based on predefined research questions, a consideration of $a$ priori constructs, and ... [develops] testable hypotheses." Process models and variance models, which are the subject of the paper by Shaw and Jarvenpaa, are used in a distinctly hypothetico-deductive manner. The supposed distinction between positivism and interpretivism is blurred by research such as that of Romm and Pliskin who demonstrate that the combination of data analysis techniques and situational interpretation are appropriate when trying to gain an understanding of "playing politics with e-mail." In personal correspondence with us concerning a reviewer's comment on her paper, Trauth responded, "I am more on the positivist side of the positivist-relativist continuum than Referee 10 ... [and] for that I do not think I need to defend myself." In other words, qualitative IS researchers are proceeding with maturity and open minds, willing to adopt and adapt forms of positivism for qualitative research even though, at one time, self-styled positivist IS researchers had perjoratively and imperialistically dismissed all qualitative research as "unscientific." We read this acceptance of what was once seen as the archenemy of qualitative research as a sign that the domain of qualitative IS research 
has cast off its defensiveness, is secure in its development, and has already commenced a process of maturation. Similarly, the "hybrid models" of Shaw and Jarvenpaa, which constitute a refutation to and transgression of the previously rigid and nonoverlapping categories of process and variance models, is a manifestation of an emerging acceptance of diversity. Gallivan explicates different approaches to triangulation using quantitative and qualitative methods that reveals diversity even within triangulation.

Third, there is the significance of the theme of evaluating qualitative research which underlies this volume. A distinguishing feature here is that we are deliberately reflecting on the accomplishments of qualitative IS research since the times of the Manchester and Copenhagen meetings. With this in mind, we invited M. Lynne Markus to give the keynote address at the Philadelphia meeting of IFIP 8.2, and we commissioned papers specifically to assess what various qualitative approaches have achieved since the mid-1980s. Markus's paper provides a grand tour of how well qualitative IS research has fared, and also how much more remains to be done.

The papers prepared for the Philadelphia meeting of IFIP 8.2 are both retrospective and contemporary. ${ }^{1}$ The retrospective elements were to a large extent contrived. We indirectly commissioned four assessment pieces, one of which, the paper on ethnography by Prasad, appears here. This was arranged and edited by Wanda Orlikowski. Another commissioned work, arranged by Boon Siong Neo, is on case research and authored by John King and Lynda Applegate. As it is written in the form of hypertext, it does not appear in this volume, but is available on the world wide web via the home page of IFIP Working Group 8.2. The two remaining commissioned assessment papers on critical social theory and action research did not survive the rigors of the review process, but highlights of a special panel in the program on critical social theory will be made available on the world wide web. Fortunately, an excellent paper on action research came to our attention. Its author, Francis Lau, accepted our invitation to present it as one of the assessment papers at the Philadelphia meeting. In addition to the commissioned works, the paper by Shaw and Jarvenpaa includes a reflective assessment of twenty-eight IS studies that make use of process models, in addition to their own contribution to the process theory approach itself. Because of the quality and theme of that work, it too is being presented as one of the assessment papers.

A collection of papers of this sort could have been organized in a number of ways, and the current structure is by no means the only appropriate one. Two good alternatives to the one used in this book were suggested at a brainstorming session at the December, 1996, meeting of IFIP Working Group 8.2 just prior to the annual Interna-

\footnotetext{
${ }^{1}$ Sixty papers and panel proposals were submitted to this conference. Along with the program committee members and a few additional experts who served as the referees, we applied the same reviewing practices and standards as for journal submissions. Of the sixty submissions, we conditionally accepted twenty papers and one panel (by Kaplan, Lau, Aarts, and Forsythe). After revisions, we accepted them for publication in this volume.
} 
tional Conference on Information Systems in Cleveland. For each of the three proposed ways of organizing the papers, the astute participants pointed out where the proposed categories were imperfect, suggested different categories under which certain papers could be classified, noted the overlap of some categories, and revealed where the given categories did not satisfactorily classify one or another paper. In one alternative, there were just three categories: methodological criticism, methods, and practice. Another organizing framework consisted of five categories, the first three corresponding to stages in the research process: theorizing, collecting, and analyzing. The other two stages would cut across these to gather papers which provide frames and those which express arenas. All such categorizations, including the one we are using, suffer from some unevenness and a lack of fit. Furthermore, scholars who submitted papers for publication in this volume did not have any of these categories in mind when they wrote their pieces.

The structure which you have before you does require some explanation. First, it is grounded on the presentational categories which the authors themselves imply through the content of their work. The result is a long list of headings, but it is comprehensibly ordered. The first, Overviewing and Assessing Qualitative IS Research, includes the specifically assessment papers, those by Prasad, by King and Applegate, by Shaw and Jarvenpaa, and by Lau, and also the grand-tour assessment paper by Markus. The next heading, Interpretation and IS Requirements Definition contains the papers by Davidson, by Urquhart, and by Westrup. Illustrating, Experiencing, and Being Critical in Ethnography gathers together papers by Harvey, by Myer, by Ruhleder, and by Trauth. Interviewing and the Interviewer brings the paper by Janson, Guimaraes, Brown and Taillieu next to the one by Mantelaers. Three papers addressing The Social and Political Context of IS are those by Sawyer, by Silva and Backhouse, and by Romm and Pliskin. Developments in Qualitative Methods is a grouping of specifically methodological papers by Ang and Endeshaw, by Garcia and Quek, by Introna and Whitley, by Vidgen and Braa, by Walsham, by Gallivan, and by Paré and Elam.

\section{OVERVIEWING AND ASSESSING QUALITATIVE IS RESEARCH}

In a sense, all Working Conferences of 8.2 are about qualitative research. The Philadelphia meeting is distinct, however, because of the purposely self-reflective and evaluative stance it takes on qualitative approaches and their history in the information systems field. Markus, in the text of her keynote address, celebrates the status of widespread acceptance of qualitative research in the world of information systems researchers and calls for qualitative researchers to accept diversity in research approaches amongst ourselves; however, unlike other calls to (or criticisms of) diversity in information systems research, Markus additionally identifies the need for a "convergence on content," where attention to technological details is needed not only to develop good understandings of information systems, but also to differentiate ourselves from other fields that are becoming increasingly interested in the study of 
information technology. King and Applegate, whose overview and assessment paper about case research is written in hypertext and is available through a pointer on a World Wide Web page at www.isr.uci.edu, also acknowledges the acceptance of qualitative approaches, but that "qualitative research is viewed as a privilege reserved for those with tenure"; presented in the form of a case itself, their paper allows the reader to examine not only the epistemological and methodological debates, but also the politics of research, with which an untenured Assistant Professor must struggle when pursuing qualitative research in information systems. Looking less at the political context of doing research and more at its content, Lau's paper provides a somewhat dazzling overview and assessment of action research in information systems studies reported in literature over the last 25 years; he concludes by proposing a contemporary information-systems action research framework as a conceptual foundation and practical guide for researchers and practitioners interested in action research for information-systems studies. Shaw and Jarvenpaa, in their overview and assessment of information systems studies, describe and categorize over a score of such studies; whereas the annotation of the studies is useful in itself as a guide to the literature, the paper by Shaw and Jarvenpaa is no less useful citing instances of studies that combine elements of both process-theory research and variance-theory research, where these instances refuting any claims that hybrid research (combining elements of both process and variance research) is undesirable or inferior. In the final paper in this section, Prasad provides an overview of ethnography as a methodology to study information technologies and contrasts ethnography with other commonly used qualitative field research methods; her paper delves into features of qualitative research that lead some to call it intensive: the concern for "thick description," the plausibility of accounts, and the cultural context and the immersion of the researcher.

\section{INTERPRETATION AND IS REQUIREMENTS DEFINITION}

The three strong papers on requirements definition provide an excellent model for how to apply qualitative methods to a mainstream systems development problem. Through longitudinal, in-depth, qualitative field studies of information systems delivery processes, Davidson shows not only how appropriate data are collected, she also explains how it can be analyzed, using techniques honed in the analysis of narrative. A different narrative approach is taken by Urquhart, who uses a form of grounded theory to structure the interpretation of a set of dialogues. These interactions between analyst and client are presented in the form of an unfolding plot where features of the encounter are redefined and presented to check with participants that their intent had been properly represented. Another view of users is presented by Westrup, whose concern is to develop the methods devised by Enid Mumford and those which have come to be known as the Scandinavian cooperative approach for capturing the underlying goals of participants in the process of systems development. Here the capturing process involves a reinterpretation of the expressions of differing participants in the systems development process. 


\section{ILLUSTRATING, EXPERIENCING, AND BEING CRITICAL IN ETHNOGRAPHY}

Myers encourages us to see the advantages of ethnographic methods. They get behind the reasoning of the participants, they have the advantages of structuralist techniques, and they are nonjudgmental. Walsham, judging by his contribution to this volume, would claim that it is not quite so easy, but at least we can see from Myers how immersion techniques work from his brief description of one case. Harvey manages, without being unduely self referential, to reflect ethnographically upon ethnography and does so by the use of Orlikowski's early work in the field. Although there is a potential for loops within loops of self consideration, Harvey avoids this by linking her interpretation of the process of ethnography to both pedagogical and methodological reasoning. Again, it shows that there are no shortcuts to the process of "getting inside." Another approach to explaining the problem of getting inside is that of Trauth, who reflects upon her own heartfelt experiences and provides many useful methodological pointers to prospective newcomers to ethnography. Those pointers have to some extent been anticipated by Ruhleder and Jordan, who demonstrate excellent research methods in their application of video-based interaction analysis to ethnography.

\section{INTERVIEWING AND THE INTERVIEWER}

Good interviewing techniques have stood at the base of much successful qualitative research in many social studies disciplines. The papers by Mantelaers and by Janson, Guimaraes, Brown and Taillieu demonstrate how such best practices can be used within information systems research. Mantelaers takes us through the steps in part of the design of an interview-based system design procedure. Here the pitfalls of various approaches are described and the specific advantages of proper elicitation techniques are demonstrated. Good elicitation was necessary for the Colruyt case presented by Janson et al. By quoting at length from the interviews themselves, we can see clearly how far in-depth they were able to go. Readers of this volume will have the opportunity to assess the relationship between the explicitly ethnographical approaches covered in the preceding section with the technique based approach of these studies of interviewing.

\section{THE SOCIAL AND POLITICAL CONTEXT OF IS}

Silva and Backhouse believe that "qualitative research in information systems should be led by theories grounded in interpretive and phenomonelogical premises to make sense and to be consistent." Theirs is an application of actor-network theory which, with three appearances in this volume (see also the papers by Walsham and by Introna and Whitley), might be regarded as a trend, at least among qualitative researchers in Britain. Appropriately, longitudinal analyses have been adopted by Romm and Pliskin 
as well as Sawyer and Southwick as the means of charting changing political pressures in organizations.

\section{DEVELOPMENTS IN QUALITATIVE METHODS}

Actor-network theory reappears in Walsham's paper, which draws together its features to help us make sense of its increasingly awkward and inconclusive application to IS research. His proposals are explicit and would affect many procedural matters if they were to take hold, such as the encouragement of longer texts and more detailed case studies. He also stresses the real distinction between morally judgmental analyses and other forms of research. It is not all that easy to have it both ways. Vigden and Braa advocate a means of adapting action research so that it can become useful as a realistic research strategy through the "action case." This is an advantage to doctoral students and, through their clear guidelines, to those who would need well delineated research practices.

There are many surprising results scattered throughout the papers in this volume. However, perhaps the most surprising result can be seen in the aggregate of qualitative research in the 1990s. Here, finally, we see the end of meek and tentative forays into qualitative methods as applied to information systems. No longer do we have to look to a very small group of pioneers who import methods from elsewhere. Now we can claim that there is a healthy and highly productive element of the study of information systems which draws maturely upon the best of a wide range of social investigative techniques.

\section{BIOGRAPHY}

Allen S. Lee is the Paul Paré Professor of MIS at McGill University and a senior editor at MIS Quarterly. A theme throughout his research has been the advancement of qualitative, interpretive, and case approaches in information systems research and their constructive relationship to quantitative, positivist, and large-sample approaches. He has published in MIS Quarterly, Organization Science, Human Relations, Information \& Management, and The Computer Journal. He earned his doctorate at the Massachusetts Institute of Technology, his master's degree at the University of California at Berkeley, and his bachelor's degree at Cornell University.

Jonathan Liebenau is a Senior Lecturer in Information Systems and Chairman of the Information Society Observatory at the London School of Economics and Political Science. He is editor of the European Journal of Information Systems and has written eight books, including Understanding Information (with James Backhouse, London: Macmillan, 1990) and Information Technology Policies and Applications in Commonwealth Developing Countries (with G. Harindranath, London: Commonwealth Secretariat, 1993). He concentrates on two areas, information technology and economic development, and theories of information. 